\title{
Anthropometric measures of increased central and overall adiposity in association with echocardiographic left ventricular hypertrophy
}

\author{
Sérgio Lamego Rodrigues ${ }^{1}$, Marcelo Perim Baldo ${ }^{1}$, Roberto Sá Cunha ${ }^{1}$, Lílian CS Angelo ${ }^{2}$, \\ Alexandre C Pereira ${ }^{2}$, José Eduardo Krieger ${ }^{2}$ and José Geraldo Mill ${ }^{1}$
}

Left ventricular hypertrophy is an important predictor of cardiovascular risk and sudden death. This study explored the ability of four obesity indexes (body mass index, waist circumference, waist-hip ratio and waist-stature ratio) to identify left ventricular hypertrophy. A sample of the general population ( $n=682 ; 43.5 \%$ men) was surveyed to assess cardiovascular risk factors. Biochemical, anthropometric and blood pressure values were obtained in a clinic visit according to standard methods. Left ventricular mass was obtained from transthoracic echocardiogram. Left ventricular hypertrophy was defined using populationspecific cutoff values for left ventricular mass indexed to height ${ }^{2.7}$. The waist-stature ratio showed the strongest positive association with left ventricular mass. This correlation was stronger in women, even after controlling for age and systolic blood pressure. By multivariate analysis, the main predictors of left ventricular hypertrophy were waist-stature ratio (23\%), systolic blood pressure $(9 \%)$ and age $(2 \%)$ in men, and waist-stature ratio $(40 \%)$, age $(6 \%)$ and systolic blood pressure $(2 \%)$ in women. Receiver-operating characteristic curves showed the optimal cutoff values of the different anthropometric indexes associated with left ventricular hypertrophy. The waist-stature ratio was a significantly better predictor than the other indexes (except for the waist-hip ratio), independent of gender. It is noteworthy that a waist-stature ratio cutoff of 0.56 showed the highest combined sensitivity and specificity to detect left ventricular hypertrophy. Abdominal obesity identified by waist-stature ratio instead of overall obesity identified by body mass index is the simplest and best obesity index for assessing the risk of left ventricular hypertrophy, is a better predictor in women and has an optimal cutoff ratio of 0.56 .

Hypertension Research (2010) 33, 83-87; doi:10.1038/hr.2009.188; published online 13 November 2009

Keywords: abdominal adiposity; body mass index; left ventricular hypertrophy

\section{INTRODUCTION}

The epidemic of overweight/obesity caused by lifestyle changes associated with economic expansion and urbanization ${ }^{1}$ is challenging developing countries with a dramatic increase in morbidity and mortality from cardiovascular diseases, ${ }^{2}$ especially in middle-aged productive individuals. ${ }^{3}$ Obesity is frequently associated with the development of hypertension, type II diabetes mellitus, and cardiovascular and kidney diseases, ${ }^{4,5}$ as well as changes in the cardiac structure. ${ }^{6}$ In epidemiological studies, the evaluation of obesity has been accomplished using anthropometric measures. ${ }^{7}$ In addition to difficulties in establishing a consensual definition of obesity, ${ }^{8}$ the most useful specific aspect of increased adiposity to indicate high cardiovascular risk is also controversial. The measures used include body mass index ${ }^{9}$ for total body adiposity, waist circumference ${ }^{10}$ for central adiposity or some normalized obesity index such as the waist-hip ratio $^{11}$ or the waist-stature ratio. ${ }^{12}$

Due to the economic and health burdens involved with cardiovascular disease, ${ }^{13}$ every effort should be made to identify abnormal health conditions before the appearance of clinical symptoms to reduce their toll. ${ }^{14,15}$ The aim is to identify a phenotype related to left ventricular hypertrophy using a simple, cheap measure that is easily interpreted and could then be carried out in the population in health promotion and prevention of cardiovascular risk factors programs. Our aim was to establish the association between echocardiographic left ventricular hypertrophy and anthropometric parameters of increased adiposity in a population-based study to find the best measure and its cutoff values using receiver-operating characteristics (ROC) curve analysis.

\section{METHODS}

Study design and population

We performed a cross-sectional study of risk factors for cardiovascular diseases among the urban population of Vitoria, Espírito Santo, Brazil, according to the guidelines of the MONICA-WHO project. ${ }^{16}$ The study design was based on cross-sectional research methodology and was developed by means of surveying health data in a probabilistic sample of residents from the municipality of

${ }^{1}$ Department of Physiological Sciences, Federal University of Espírito Santo, Espírito Santo, Brazil and ${ }^{2}$ Heart Institute, University of São Paulo, São Paulo, Brazil Correspondence: Professor SL Rodrigues, Department of Physiological Sciences, Federal University of Espírito Santo, Av. Marechal Campos 1468, Maruípe, 29042-751 Vitória, Espírito Santo, Brazil. 
Vitoria, Espírito Santo, Brazil. A total of 1662 individuals (25-64 years), representative of the population, were surveyed in 1999-2001. All first-phase participants were invited to a health reevaluation 5 years later. A total of 682 subjects agreed to participate and were reassessed by the same methodology. In addition, they were requested to have an echocardiogram. The investigation of the second-phase subjects is the main focus of this study. Supplementary information related to sample selection and examinations is available in earlier publications. ${ }^{17,18}$

The project was approved by the institutional ethics committee and all participants gave informed written consent.

\section{Measurements}

Blood pressure was measured during the morning period (0700 to 0900 hours) in fasting individuals in a seated position using a standard mercury sphygmomanometer on the left arm after a 5- to 10-min rest period. Mean values of systolic and diastolic blood pressure were calculated from two measurements carried out by two independent trained staff members, with a minimal interval of $10 \mathrm{~min}$ between the two measures. Subjects were considered hypertensive if they had a systolic blood pressure $\geqslant 140 \mathrm{~mm} \mathrm{Hg}$, a diastolic blood pressure $\geqslant 90 \mathrm{~mm} \mathrm{Hg}$ or if they used antihypertensive drugs, including diuretics.

A fasting venous blood sample was collected soon after blood pressure measurements to determine glucose, triglycerides, total cholesterol, highdensity lipoprotein (HDL)-cholesterol and creatinine using validated commercial kits. Diabetes was defined in patients using antidiabetic medication and/or with a fasting blood glucose $\geqslant 126 \mathrm{mg}$ per $100 \mathrm{ml}$.

Anthropometric parameters were obtained by trained technicians using standard methods. ${ }^{19}$ Body weight was taken on a calibrated scale to the nearest $0.1 \mathrm{~kg}$. Height was taken with a wall-mounted stadiometer to the nearest $0.5 \mathrm{~cm}$. Body mass index was calculated as body weight in $\mathrm{kg} \mathrm{m}^{-2}$ and obesity was defined as body mass index $\geqslant 30 \mathrm{~kg} \mathrm{~m}^{-2}$. Waist circumference was measured at the mean point between the lowest rib margin and the iliac crest with the subject standing and at the maximum point of normal expiration. Sexspecific partition values ( $\geqslant 102$ and $\geqslant 88 \mathrm{~cm}$ for men and women, respectively) were used as cutoff values for central obesity. The waist-stature ratio was calculated by dividing the waist circumference (in $\mathrm{cm}$ ) by the baseline height (in $\mathrm{cm}$ ). Hip circumference was measured to the nearest $0.1 \mathrm{~cm}$ around the thighs at the height of the greater trochanter, with subjects in a standing position.

Echocardiography measurements were performed on each subject using a commercially available Acuson Sequoia Ultrasound system with a 2- to 3.5$\mathrm{MHz}$ transducer (Acuson, Mountain View, CA, USA). All examinations were performed by the same physician, who was blind to the individuals' clinical and biochemical data. The procedure was carried out at rest with the subject in the left lateral decubitus position. Using the second harmonic imaging and twodimensional guided M-mode measurements, left ventricular end diastolic diameter (LVEDD), interventricular septum thickness (IVST) and posterior wall thickness (PWT) were obtained, following the recommendations of the American Society of Echocardiography. ${ }^{20}$ Crude left ventricular mass was calculated according to the American Society of Echocardiography corrected formula: ${ }^{21}$ left ventricular mass $=0.80 \times\left(1.04 \times(\text { LVEDD+IVST }+ \text { PWT })^{3}-\right.$ $\left.(\text { LVEDD })^{3}\right)+0.6 \mathrm{~g}$. All values were registered in $\mathrm{mm}$ and each measure was recorded as an average of three consecutive cardiac cycles. Left ventricular mass was indexed to height raised to the power 2.7. ${ }^{22,23}$ Randomly selected examinations (35) were submitted to a second observer, also blind to the clinical data. The agreements among examinations were analyzed by the differences between measures according to the Bland-Altman method, ${ }^{24}$ and more than $95 \%$ of the differences of the echocardiographic measurements (septum, posterior wall, systolic and diastolic left ventricle diameters) were within 1.96 standard deviations of the mean. The differences found between the two investigators were not clinically relevant. The cutoff points to define increased left ventricular mass were the values corresponding to the 95th percentile of the normal distribution curve obtained from a healthy subsample. The values for crude left ventricular mass were $\geqslant 197.2$ and $\geqslant 162.9 \mathrm{~g}$ for men and women, respectively. The indexed values were $\geqslant 47.7$ and $46.6 \mathrm{~g} \mathrm{~m}^{-2.7}$, $\geqslant 113.4$ and $108.2 \mathrm{~g} \mathrm{~m}^{-2}$ and $\geqslant 105.3$ and $100.1 \mathrm{~g} / \mathrm{m}^{2}$ for men and women, respectively. ${ }^{25}$ The values are similar to those reported by Ilercil et al. ${ }^{26}$
Obesity parameters were analyzed in relation to left ventricular mass indexed to height ${ }^{2.7}, 22$ which detects obesity related left ventricular hypertrophy better than left ventricular mass corrected for body surface area. ${ }^{21,27}$ Individuals with technically unsatisfactory echocardiography or with incomplete anthropometric or clinical data $(n=41)$ were excluded from the analysis.

\section{Statistical analysis}

Analyses were performed with the SPSS 13.0 package (Chicago, IL, USA). Data were described separately for gender as means \pm standard deviation for continuous variables and proportions to dichotomous variables. The goodness of fit to a normal distribution was evaluated using the Kolmogorov-Smirnov test. Body mass index and triglycerides were analyzed after logarithmic transformation. Unpaired Student's $t$-test and the $\chi^{2}$-test were used to compare continuous and categorical variables, respectively. Total and partial correlation analyses (Pearson) were performed to estimate associations between anthropometric indexes and left ventricular mass. The model was adjusted for systolic blood pressure and age. Multivariate stepwise regression analysis was used to determine which obesity indexes were independently associated with left ventricular mass variability. The prediction ability of obesity measures and the sensitivities and specificities of the indexes were identified by ROC curve analysis. ${ }^{28}$ Differences of the areas under the ROC curve were compared using a method previously described. ${ }^{29}$ Optimal cutoff points were registered as the measures representing the largest concomitant sensitivity and specificity. ${ }^{30}$ $P$-values less than 0.05 were considered statistically significant.

\section{RESULTS}

\section{Baseline characteristics}

Clinical and demographic characteristics of the sample are shown in Table 1. Most variables analyzed were significantly higher in men, except for age, glycemia, waist-stature ratio, left ventricular mass indexed to height ${ }^{2.7}$ and the prevalence of current smokers, which were similar in both genders. Cholesterol and HDL levels were lower in men than in women.

The prevalence of left ventricular hypertrophy, defined by a partition coefficient unrelated to body surface area $\left(\mathrm{g} \mathrm{m}^{-2.7}\right)$, was $23.8 \%$, without statistical difference between genders (20.3 and $26.4 \%$ for

Table 1 Clinical and anthropometric variables of the sample stratified by gender

\begin{tabular}{|c|c|c|c|}
\hline Variables & Men $(n=277)$ & Women $(n=364)$ & P-value \\
\hline Age (years) & $51.3 \pm 10.6$ & $51.3 \pm 10.2$ & 0.91 \\
\hline Systolic blood pressure $(\mathrm{mm} \mathrm{Hg})$ & $133.8 \pm 18.5$ & $127.5 \pm 19.4$ & 0.00 \\
\hline Diastolic blood pressure $(\mathrm{mm} \mathrm{Hg})$ & $88.7 \pm 11.5$ & $83.0 \pm 11.9$ & 0.00 \\
\hline Glucose (mg per $100 \mathrm{ml}$ ) & $95.6 \pm 20.3$ & $96.5 \pm 31.4$ & 0.70 \\
\hline Creatinine (mg per $100 \mathrm{ml}$ ) & $1.1 \pm 0.3$ & $0.9 \pm 0.2$ & 0.00 \\
\hline Cholesterol (mg per $100 \mathrm{ml}$ ) & $198.4 \pm 37.7$ & $205.9 \pm 40.5$ & 0.01 \\
\hline HDL-cholesterol (mg per $100 \mathrm{ml}$ ) & $42.0 \pm 9.9$ & $49.8 \pm 11.7$ & 0.00 \\
\hline Triglyceride (mg per $100 \mathrm{ml}$ ) & $177.4 \pm 105.9$ & $138.4 \pm 74.5$ & 0.00 \\
\hline Body mass index $\left(\mathrm{kg} \mathrm{m}^{-2}\right)$ & $26.1 \pm 3.6$ & $26.9 \pm 5.3$ & 0.04 \\
\hline Waist circumference $(\mathrm{cm})$ & $91.1 \pm 9.9$ & $85.0 \pm 13.1$ & 0.00 \\
\hline Waist-stature ratio & $0.54 \pm 0.06$ & $0.54 \pm 0.08$ & 0.42 \\
\hline Waist-hip ratio & $0.92 \pm 0.07$ & $0.83 \pm 0.09$ & 0.00 \\
\hline Left ventricular mass, crude (g) & $170.9 \pm 42.7$ & $136.4 \pm 36.8$ & 0.00 \\
\hline Left ventricular mass $\left(\mathrm{g} \mathrm{m}^{-2.7}\right)$ & $41.9 \pm 11.0$ & $41.1 \pm 11.7$ & 0.40 \\
\hline Left ventricular mass $\left(\mathrm{g} \mathrm{m}^{-2}\right)$ & $92.6 \pm 21.3$ & $82.9 \pm 20.4$ & 0.00 \\
\hline Arterial hypertension (\%) & 55.6 & 43.6 & 0.00 \\
\hline Obesity, $\mathrm{BMI} \geqslant 30 \mathrm{~kg} \mathrm{~m}^{-2}(\%)$ & 15.1 & 23.9 & 0.05 \\
\hline Current smoker (\%) & 19.8 & 14.8 & 0.08 \\
\hline
\end{tabular}

Abbreviations: BMI, body mass index; HDL, high-density lipoprotein; $n=$ number of subjects. Data described as mean \pm s.d. or percentage $(\%)$. 
men and women, respectively, $\left.X^{2}=0.07\right)$. Left ventricular hypertrophy was detected in $7.9 \%$ of normotensive and $40 \%$ of hypertensive individuals. Normotensive subjects with increased abdominal adiposity had five times more left ventricular hypertrophy when compared with the normal waist circumference group (25 and 5\%, respectively; data not shown). Only $27 \%$ of hypertensive subjects were using angiotensin-converting enzyme inhibitors or angiotensin II receptor blockers.

Total and partial correlations of left ventricular mass with anthropometric indexes

We investigated the association of the anthropometric indexes with left ventricular mass normalized to height ${ }^{2.7}$. Waist-stature ratio showed a positive and overall better correlation in both genders and was a stronger predictor in women, even after adjustment for age and systolic blood pressure (Table 2).

\section{ROC curve analysis}

Figure 1 shows the ROC curves for body mass index, waist circumference, waist-hip ratio and waist-stature ratio with regard to the ability to identify left ventricular hypertrophy $\left(\mathrm{g} \mathrm{m}^{-2.7}\right)$ in men and women. There was a significant waist-stature ratio superiority in relation to the other indexes $(P<0.05)$ (except for the waist-hip ratio), independent of gender.

Table 3 shows the areas under the ROC curves and the optimal anthropometric index partition points (according to the highest sensitivity and specificity) to identify left ventricular hypertrophy $\left(\mathrm{g} \mathrm{m}^{-2.7}\right)$. There was roughly the same body mass index cutoff $\left(\sim 27 \mathrm{~kg} \mathrm{~m}^{-2}\right)$, a $6-\mathrm{cm}$ difference in waist circumference (93 and $87 \mathrm{~cm})$ and a 0.08 difference in waist-hip ratio $(0.94$ and 0.86$)$ for men and women, respectively. The waist-stature ratio (0.56) was similar for both genders. It is worth noting that the waist-stature ratio showed the highest combined sensitivity and specificity, with values above 70 and $75 \%$ for men and women, respectively. The waiststature ratio index (0.56) showed $69 \%$ sensitivity and $82.3 \%$ specificity in the ability to identify left ventricular hypertrophy in normotensive subjects, whereas in hypertensive individuals the sensitivity and specificity were 77 and $61 \%$, respectively (data not shown).

\section{Multivariate regression analysis}

Predictors of left ventricular mass variability $\left(\mathrm{g} \mathrm{m}^{-2.7}\right)$ were investigated by multivariate stepwise regression analysis, stratified by gender. The model was adjusted for age and systolic blood pressure. In men, the waist-stature ratio $(\beta=0.515, P<0.001)$, systolic blood pressure $(\beta=0.273, P<0.001)$ and age $(\beta=0.198, P<0.001)$, explained 23 ,

Table 2 Pearson correlation coefficients $(r)$ between left ventricular mass indexed to height ${ }^{2.7}$ and obesity indexes

\begin{tabular}{|c|c|c|c|c|c|c|c|c|}
\hline \multirow[b]{3}{*}{ Variables } & \multicolumn{4}{|c|}{ Men } & \multicolumn{4}{|c|}{ Women } \\
\hline & \multirow[b]{2}{*}{$r$} & \multirow[b]{2}{*}{ P-value } & \multicolumn{2}{|c|}{ Partial correlation } & \multirow[b]{2}{*}{$r$} & \multirow[b]{2}{*}{ P-value } & \multicolumn{2}{|c|}{ Partial correlation } \\
\hline & & & r & P-value & & & r & $\mathrm{P}$-value \\
\hline BMI & 0.39 & $<0.001$ & 0.30 & $<0.001$ & 0.54 & $<0.001$ & 0.52 & $<0.001$ \\
\hline WC & 0.36 & $<0.001$ & 0.23 & $<0.001$ & 0.57 & $<0.001$ & 0.51 & $<0.001$ \\
\hline WHR & 0.38 & $<0.001$ & 0.21 & $<0.001$ & 0.50 & $<0.001$ & 0.40 & $<0.001$ \\
\hline WSR & 0.46 & $<0.001$ & 0.32 & $<0.001$ & 0.63 & $<0.001$ & 0.57 & $<0.001$ \\
\hline
\end{tabular}

Abbreviations: BMI, body mass index; WC, waist circumference; WHR, waist-hip ratio; WSR, waist-stature ratio.

Partial correlation: adjusted for age and systolic blood pressure.
9 and $2 \%$ of left ventricular mass variability, respectively. In women, waist-stature ratio $(\beta=0.957, P<0.001)$, age $(\beta=0.214, P<0.001)$ and systolic blood pressure $(\beta=0.171, P<0.001)$ explained 40,6 and $2 \%$ of left ventricular mass variability, respectively. The predictive strength of the waist-stature ratio was not changed with the inclusion or exclusion of systolic blood pressure from the model.

\section{DISCUSSION}

The prevalence of abdominal adiposity and overall obesity is increasing, with an immense personal and economic cost. ${ }^{31}$ The cost is driven
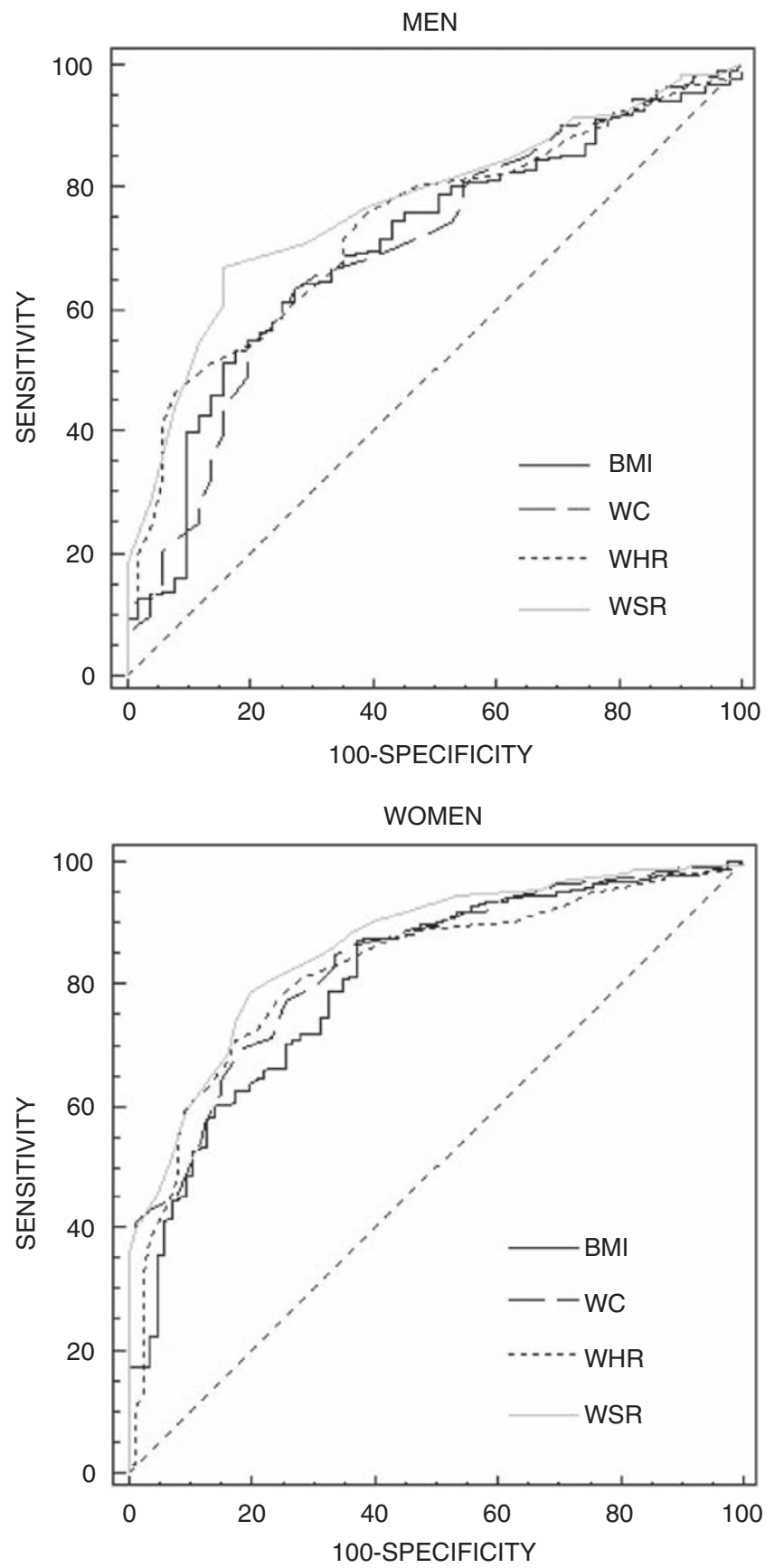

Figure 1 Receiver-operating characteristic curves of body mass index, waist circumference, waist-hip ratio and waist-stature ratio in relation to left ventricular hypertrophy ( $\left(\right.$ height $^{-2.7}$ ) in men and women. 
Table 3 Areas under the ROC curve, cutoffs, sensitivity and specificity of anthropometric indexes to predict left ventricular hypertrophy (mass indexed to height ${ }^{2.7}$ )

\begin{tabular}{|c|c|c|c|c|c|c|}
\hline & $A \cup R C$ & $95 \% \mathrm{Cl}$ & P-value & Cutoff & Sensitivity & Specificity \\
\hline \multicolumn{7}{|l|}{ Men } \\
\hline BMI & 0.703 & $(0.645-0.756)$ & $0.018^{\mathrm{a}}$ & 26.73 & 0.65 & 0.68 \\
\hline WC & 0.698 & $(0.640-0.752)$ & $0.001^{\mathrm{a}}$ & 93.15 & 0.71 & 0.66 \\
\hline WHR & 0.737 & $(0.680-0.788)$ & NS & 0.94 & 0.65 & 0.66 \\
\hline WSR & 0.771 & $(0.717-0.819)$ & - & 0.56 & 0.73 & 0.71 \\
\hline \multicolumn{7}{|l|}{ Women } \\
\hline BMI & 0.805 & $(0.761-0.845)$ & $0.002^{\mathrm{a}}$ & 26.91 & 0.71 & 0.71 \\
\hline WC & 0.834 & $(0.792-0.871)$ & $0.004^{\mathrm{a}}$ & 86.80 & 0.73 & 0.72 \\
\hline WHR & 0.823 & $(0.780-0.861)$ & NS & 0.86 & 0.75 & 0.75 \\
\hline WSR & 0.863 & $(0.823-0.897)$ & - & 0.56 & 0.77 & 0.77 \\
\hline
\end{tabular}

Abbreviations: AURC, area under the ROC curve; BMI, body mass index; WC, waist circumference; WHR, waist-hip ratio; WSR, waist-stature ratio.

aln relation to WSR.

by obesity-related increases in risk for conditions such as insulin resistance, dyslipidemia and systemic inflammation, all of which are essential in the pathogenesis of cardiovascular disease, metabolic syndrome and some types of cancer. ${ }^{32,33}$ Changes in the left ventricular structure such as hypertrophy, which is a potent marker of end-organ damage, ${ }^{34}$ have been reported with increased adiposity. ${ }^{6}$ The presence of left ventricular hypertrophy strongly predicts bad cardiovascular outcomes, both in the presence and in the absence of metabolic syndrome and/or diabetes and independently of hypertension. ${ }^{35}$

Our study shows that all adiposity measures have a positive association with left ventricular mass even after adjustments for age and systolic blood pressure. However, the waist-stature ratio presented the best correlation and was identified as the major determinant of left ventricular mass regardless of gender, although both findings are stronger in women. Our data are in accordance with a recent study reporting that the hypertrophic left ventricular phenotype was better predicted in women with increased abdominal adiposity, independent of body size. ${ }^{36}$

Body mass index has been used as an obesity index in many other studies. However, its ability to predict or to be associated with hypertension, metabolic syndrome or left ventricular hypertrophy has been questioned. ${ }^{37,38}$ Furthermore, although some studies have explored the associations between cardiovascular risk and anthropometric indexes other than body mass index, analytic approaches and results have been inconsistent and most studies have not directly compared multiple indexes. ${ }^{39}$

Our study suggests that the established cutoff points for categorizing the population as overall or centrally obese seem not to be appropriate. Indeed, $63 \%$ of men and $95 \%$ of women classified as obese by body mass index were also obese by waist circumference, whereas only $73 \%$ of men and $60 \%$ of women deemed obese by waist circumference were also obese by body mass index (data not shown). Even though body mass index and waist circumference have a high correlation ( $r=0.88$ for both genders, $P<0.001$ ), $40 \%$ of women with abdominal obesity would be missed by body mass index obesity criteria. These discrepancies were also reported in other studies. ${ }^{40,41}$

Multiple biological mechanisms have been implicated in mediating the adverse health effects of excess adiposity; however, the exact pathways are unknown. Besides mechanisms involving secretion of adipokines and other vasoactive substances, visceral fat seems to be more sensitive to lipolysis compared with subcutaneous fat, resulting in an increased release and accumulation of free fatty acid levels in multiple organs. This contributes to insulin resistance and vascular stiffness by increasing adrenergic reactivity, vascular tone and blood pressure. ${ }^{42,43}$ Independently of arterial pressure and age, obesity increases the risk of left ventricular hypertrophy, as well as other structural abnormalities, including concentric remodeling and concentric left ventricular hypertrophy. ${ }^{44}$

Therefore, a message that must be delivered is that obesity is harmful over time, regardless of how we define or measure it. Accordingly, translating our data to the clinical practice shows an easier measurement method that is fairly well understandable by lay people and that does not require abstract concepts. Moreover, a tightening pair of pants, a belt that no longer fits and an increase in clothing size number are all easy observations that correlate with waist circumference. More important than weight or body mass index is the emerging need to observe the waistline.

Our data suggest that a cutoff point for a waist circumference with regard to left ventricular hypertrophy could be communicated to the community by simply asking individuals to multiply their stature (in $\mathrm{cm}$ ) by 0.56 and recommending a waist circumference below this measurement. We believe that this easily corrected (for the frame size) and a flexible number is more appropriate than the fixed and sexspecific waist circumference partition values currently in use.

A limitation of our study is its cross-sectional design, which does not allow us to draw conclusions in terms of causality, but rather merely shows associations between the anthropometric index and left ventricular hypertrophy. In addition, due to the ethnic characteristics of our population ( $40 \%$ white, $50 \%$ mulatto and $7 \%$ black) and the generally high sodium intake and high prevalence of hypertension, our results may not be generalized to other populations.

In conclusion, taken as a whole, our main finding is that abdominal obesity identified by the waist-stature ratio, and not overall obesity identified by body mass index, is the simplest and best obesity index for identifying echocardiographic left ventricular hypertrophy, mainly in women, with an optimal cutoff ratio of 0.56 .

1 Lanas F, Avezum A, Bautista LE, Diaz R, Luna M, Islam S, Yusuf S, the INTERHEART Investigators in Latin America. Risk factors for acute myocardial infarction in Latin America: the INTERHEART Latin American study. Circulation 2007; 115: 1067-1074.

2 Lopez A, Mathers C, Ezzati M, Jamison D, Murray C. Global Burden of Disease and Risk Factors. The World Bank and Oxford University Press: New York, NY, 2006.

3 Gaziano T. Cardiovascular disease in the developing world and its cost-effective management. Circulation 2005; 112: 3547-3553.

4 Ostlund Jr RE, Staten M, Kohrt WM, Schultz J, Malley M. The ratio of waist to hip circumference, plasma insulin level and glucose intolerance as independent predictors of the HDL cholesterol level in older adults. N Engl J Med 1990; 322: 229-234.

5 De Fronzo RA, Ferranini E. Insulin resistance: a multifaceted syndrome responsible for NIDDM, obesity, hypertension, dyslipidemia and atherosclerotic cardiovascular disease. Diabetes Care 1991; 14: 173-194.

6 Eckel RH. Obesity and heart disease: a statement for healthcare professionals from the Nutrition Committee, American Heart Association. Circulation 1997; 96: 3248-3250.

7 World Health Organization. Obesity: Preventing and Managing the Global Epidemic. Report. World Health Organization: Geneva, 1997.

8 Lesser GT, Deutsch S, Markofsky J. Use of an independent measurement of body fat to evaluate overweight and underweight. Metabolism 1971; 20: 792-804.

9 Calle EE, Thun MJ, Petrelli JM, Rodriguez C, Heath Jr CW. Body-mass index and mortality in a prospective cohort of U.S. adults. N Engl J Med 1999; 341: 1097-1105.

$10 \mathrm{Li} \mathrm{C}$, Ford ES, McGuire LC, Mokdad AH. Increasing trends in waist circumference and abdominal obesity among US adults. Obesity 2007; 15: 216-224.

11 Price GM, Uauy R, Breeze E, Bulpitt CJ, Fletcher AE. Weight, shape, and mortality risk in older persons: elevated waist-hip ratio, not high body mass index, is associated with a greater risk of death. Am J Clin Nutr 2006; 84: 449-460. 
12 Hsieh SD, Yoshinaga $\mathrm{H}$. Waist/height ratio as a simple and useful predictor of coronary heart disease risk factors in women. Intern Med 1995; 34: 1147-1152.

13 Kahn R, Robertson R, Smith R, Eddy D. The impact of prevention on reducing the burden of CVD. Circulation 2008; 118: 576-585.

14 Koren MJ, Devereux RB, Casale PN, Savage DD, Laragh JH. Relation of left ventricular mass and geometry to morbidity and mortality in uncomplicated essential hypertension. Ann Intern Med 1991; 114: 345-352.

15 Levy D, Garrison RJ, Savage DD, Kannel WB, Castelli WP. Prognostic implications of echocardiographically determined left ventricular mass in the Framingham Heart Study. N Engl J Med 1990; 322: 1561-1566.

16 Tunstall-Pedoe H, Kuulasmaa K, Amouyel P, Arveiler D, Rajakangas AM, Pajak A. Myocardial infarction and coronary deaths in the World Health Organization MONICA project. Registration procedures, event rates, and case-fatality rates in 38 populations from 21 countries in four continents. Circulation 1994; 90: 583-612.

17 Pires-de-Sousa AG, Pereira AC, Marquezini GF, Nascimento-Neto RM, Freitas SN, Nicolato RLC, Machado-Coelho GLL, Rodrigues SL, Mill JG, Krieger JE. Derivation and external validation of a simple prediction model for the diagnosis of type 2 Diabetes Mellitus in the Brazilian urban population. Eur J Epidemiol 2009; 24: 101-109.

18 Rodrigues SL, Ângelo LC, Pereira AC, Krieger JE, Mill JG. Determinants of left ventricular mass and presence of metabolic risk factors in normotensive individuals. Int J Cardiol 2009; 135: 323-330.

19 National Institute of Health. Clinical guidelines on the identification, evaluation and treatment of overweight and obesity in adults. Obes Res 1998; 6: 51S-209S.

20 Sahn DJ, De Maria A, Kisslo J, Weyman A. The Committee on M-Mode Standardization of the American Society of Echocardiography. Recommendations regarding Quantitation in M-Mode Echocardiography: results of a survey of echocardiographic measurements. Circulation 1978; 58: 1072-1083.

21 Devereux RB, Alonso DR, Lutas EM, Gottlieb GJ, Campo E, Sachs I, Reichek N. Echocardiographic assessment of left ventricular hypertrophy: comparison to necropsy findings. Am J Cardiol 1986; 57: 450-458.

22 De Simone G, Devereux RB. Gender differences in left ventricular growth. Hypertension 1995; 26: 979-983.

23 De Simone G, Kizer JR, Devereux RB. Normalization for body size and population attributable risk of left ventricular hypertrophy: The Strong Heart Study. Am J Hypertens 2005; 18: 191-196.

24 Bland JM, Altman DG. Statistical methods for assessing agreement between two methods of clinical measurement. Lancet 1986; 1: 307-310.

25 Angelo LCS, Vieira MLC, Rodrigues SL, Morelato RL, Pereira AC, Mill AC, Krieger JE. Echocardiographic reference values in a sample of asymptomatic adult Brazilian population. Arq Bras Cardiol 2007; 89: 184-190.

26 Ilercil A, O'Grady MJ, Roman MJ, Paranicas M, Lee ET, Welty TK, Fabsitz RR, Howard BV, Devereux RB. Reference values for echocardiographic measurements in urban and rural populations of differing ethnicity. The Strong Heart Study. J Am Soc Echocardiogr 2001; 14: 601-611.

27 Cuspidi C, Meani S, Negri F, Giudici V, Valerio C, Sala C, Zanchetti A, Mancia G. Indexation of left ventricular mass to body surface area and height to allometric power of 2.7: is the difference limited to obese hypertensives? J Hum Hypertens 2009; 23: 728-734.

28 Hanley JA, McNeil BJ. The meaning and use of the area under a receiver operating characteristic curve. Radiology 1982; 143: 29-36.

29 Metz CE. Basic principles of ROC curve analysis. Semin Nucl Med 1978; 8: 283-298.

30 Altman DG, Gardner M. Diagnostics tests. In: Altman DG, Machin D, Trevor NB (eds), BMJ Book, 2nd edn. 2000, pp 105-119.

31 Finkelstein EA, Fiebelkorn IC, Wang G. State-level estimates of annual medical expenditures attributable to obesity. Obes Res 2004; 12: 18-24.

32 Berg AH, Scherer PE. Adipose tissue, inflammation, and cardiovascular disease. Circ Res 2005; 96: 939-949.

33 Calle EE, Kaaks R. Overweight, obesity and cancer: epidemiological evidence and proposed mechanisms. Nat Rev Cancer 2004; 4: 579-591.

34 Devereux RB, Alderman MH. Role of preclinical cardiovascular disease in the evolution from risk factor exposure to development of morbid events. Circulation 1993; 88: 1444-1455.

35 De Simone G, Devereux RB, Chinali L, Roman MJ, Lee ET, Resnick HE, Howard BV. Metabolic syndrome and left ventricular hypertrophy in the prediction of cardiovascular events: The Strong Heart Study. Nutr Metab Cardiovas Dis 2009; 19: 98-104.

36 Tsioufis CP, Tsiachris DL, Selima MN, Dimitriadis KS, Thomopoulos CG, Tsiliggiris DC, Gennadi AS, Syrseloudis DC, Stefanadi ES, Toutouzas KP, Kallikazaros IE, Stefanadis $\mathrm{Cl}$. Impact of waist circumference on cardiac phenotype in hypertensives according to gender. Obesity 2009; 17: 177-182.

37 James WP. Assessing obesity: are ethnic differences in body mass index and waist classification criteria justified? Obes Rev 2005; 6: 179-181.

38 Franzosi MG. Should we continue to use BMI as a cardiovascular risk factor? Lancet 2006; 368: 624-625.

39 Snijder MB, van Dam RM, Visser M, Seidell JC. What aspects of body fat are particularly hazardous and how do we measure them? Int J Epidemiol 2006; 35: 83-92.

40 Cameron AJ, Welborn TA, Zimmet PZ, Dunstan DW, Owen N, Salmon J, Dalton M, Jolley D, Shaw JE. Overweight and obesity in Australia: the 1999-2000 Australian Diabetes, Obesity and Lifestyle Study. Med J Aust 2003; 178: 427-432.

41 Zhang C, Rexrode KM, Van Dam RM, Li TY, Hu FB. Abdominal obesity and the risk of all-cause, cardiovascular, and cancer mortality sixteen years of follow-up in US women. Circulation 2008; 117: 1658-1667.

42 Egan BM, Lu G, Greene EL. Vascular effects of non-esterified fatty acids: implications for the cardiovascular risk factor cluster. Prostagladins Leukot Essent Fatty Acids 1999; 60: 411-420.

43 Snijder MB, van Dam RM, Visser M, Seidell JC. What aspects of body fat are particularly hazardous and how do we measure them? Int J Epidemiol 2006; 35: 83-92.

44 Lavie CJ, Milani RV, Ventura HO, Cardenas GA, Mehra MR, Messerli FH. Disparate effects of left ventricular geometry and obesity on mortality in patients with preserved left ventricular ejection fraction. Am J Cardiol 2007; 100: 1460-1464. 